\title{
GIS-based debris flow source and runout susceptibility assessment from DEM data - a case study in NW Nicaragua
}

\author{
M. Guinau, I. Vilajosana, and J. M. Vilaplana \\ RISKNAT Research Group, Departament de Geodinàmica i Geofísica, Facultat de Geologia, Universitat de Barcelona, Zona \\ Universitària de Pedralbes, 08028, Barcelona, Spain
}

Received: 7 June 2007 - Revised: 16 November 2007 - Accepted: 16 November 2007 - Published: 26 November 2007

\begin{abstract}
In October 1998, Hurricane Mitch triggered numerous landslides (mainly debris flows) in Honduras and Nicaragua, resulting in a high death toll and in considerable damage to property. The potential application of relatively simple and affordable spatial prediction models for landslide hazard mapping in developing countries was studied. Our attention was focused on a region in NW Nicaragua, one of the most severely hit places during the Mitch event.

A landslide map was obtained at 1:10000 scale in a Geographic Information System (GIS) environment from the interpretation of aerial photographs and detailed field work. In this map the terrain failure zones were distinguished from the areas within the reach of the mobilized materials. A Digital Elevation Model (DEM) with $20 \mathrm{~m} \times 20 \mathrm{~m}$ of pixel size was also employed in the study area.

A comparative analysis of the terrain failures caused by Hurricane Mitch and a selection of 4 terrain factors extracted from the DEM which, contributed to the terrain instability, was carried out. Land propensity to failure was determined with the aid of a bivariate analysis and GIS tools in a terrain failure susceptibility map. In order to estimate the areas that could be affected by the path or deposition of the mobilized materials, we considered the fact that under intense rainfall events debris flows tend to travel long distances following the maximum slope and merging with the drainage network. Using the TauDEM extension for ArcGIS software we generated automatically flow lines following the maximum slope in the DEM starting from the areas prone to failure in the terrain failure susceptibility map. The areas crossed by the flow lines from each terrain failure susceptibility class correspond to the runout susceptibility classes represented in a runout susceptibility map.
\end{abstract}

Correspondence to: M. Guinau

(mguinau@ub.edu)
The study of terrain failure and runout susceptibility enabled us to obtain a spatial prediction for landslides, which could contribute to landslide risk mitigation.

\section{Introduction}

Landslide hazard is generally defined as the probability that a landslide may occur within a given area in a given period of time. This concept includes both spatial and time dimensions. Landslide hazard assessment is not always possible given that data on the temporal occurrence of past landslides are often not easy to obtain (Remondo et al., 2003a; Ayalew et al., 2005). Landslide susceptibility assessment is the only possibility to overcome this problem. The term susceptibility is generally used to identify the location of potential landslides in a given region based on a set of terrain characteristics. Susceptibility analysis assumes that future landslides are likely to be produced by the same conditioning factors as landslides in the past and the present (Varnes, 1984; Carrara et al., 1995). Although these methods provide information on potentially unstable slopes, they do not supply direct information on landslide magnitude and frequency.

To develop an integrate landslide susceptibility analysis, some authors such as Mongomery and Dietrich (1994), Dai et al. (2002), Chung and Fabbri (2003), Corominas et al. (2003), Coe et al. (2004), Hürlimann et al. (2006) propose the following procedure: a) evaluation of terrain failure susceptibility and b) assessment of runout behaviour of the mobilized material. The probability of the spatial occurrence for future landslides is reflected in a terrain failure susceptibility map, which indicates the potential starting zones. This map can be elaborated by heuristic, statistic (bivariate or multivariate analysis) or deterministic approaches (van Westen,

Published by Copernicus Publications on behalf of the European Geosciences Union. 


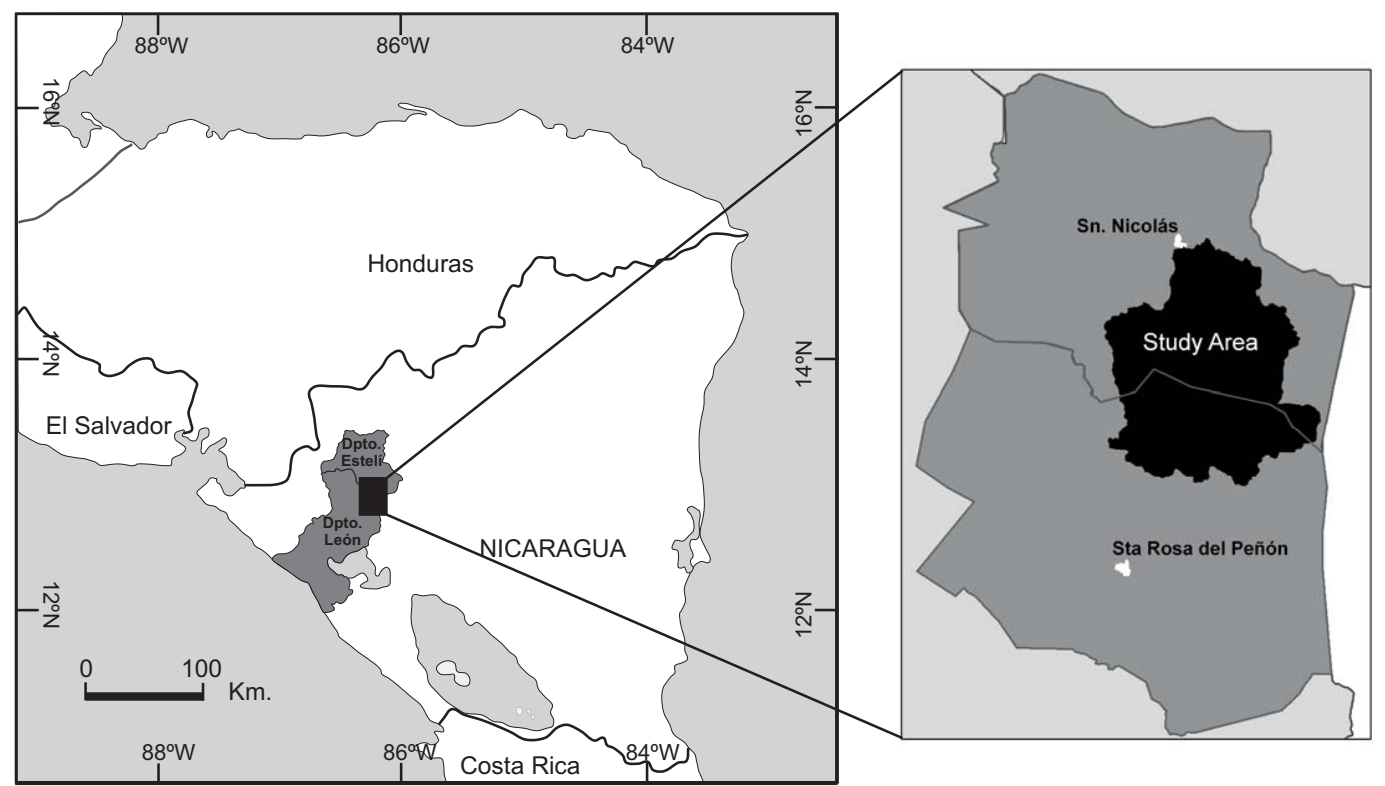

Fig. 1. Location of the Departamento de Estelí and Departamento de Leon in NW Nicaragua. In the enlarged zone, the study area (in black) and localities referred to in the text.

1993; Carrara et al., 1995; van Westen et al., 1997; Remondo et al., 2003a, Dai et al., 2002; Hürlimann et al., 2006). After determining the potential landslide initiation zones, the runout behaviour is analysed in order to delimit zones that could be reached by the mobilized debris. Approaches to assessing the mobility of debris can be empirical, analytical and numerical (Mongomery and Dietrich, 1994; Dai et al., 2002; Corominas et al., 2003; Pallàs et al., 2004; Hürlimann et al., 2006).

In many parts of the world, especially in developing countries, the scarcity of good quality data, insufficient funds and lack of specialized personnel constitute a disadvantage for landslide susceptibility and hazard assessment. Thus, there is a pressing need for developing feasible and low cost methodologies of landslide hazard assessment, which can be readily tested and implemented under the conditions found in these countries (Pallàs et al., 2004; Coe et al., 2004; Guinau et al., 2005). A number of developing countries, especially in South and Central America and Asia, are currently implementing Geographic Information Systems (GIS) and acquiring digital data, which provide advantages in geoenvironmental analysis. GIS tools enable us to produce and to handle easily a large amount of data. Digital Elevation Models (DEM) also permits the extraction of geometrical variables which can be used in landslide susceptibility assessment. Thus, DEM data would obviate the need for costly and time consuming methods required to obtain morphometric data, providing a relatively simple methodology for identifying zones potentially susceptible to debris flows.

The aims of the present study are 1) to develop a methodology for landslide susceptibility zoning considering landslide source and runout susceptibility, and 2) to provide a simple and low cost methodology that is suited to the conditions in most developing countries. This methodology could be implemented in large territories to devise policies for disaster prevention and mitigation.

\subsection{Study area}

The study area is located in the Interior Highlands of Nicaragua (Fig. 1), an extensive and heavily dissected volcanic plateau and corresponds to the upper part of the Sinecapa River basin. The area displays a hilly landscape with an average slope gradient of $20^{\circ}$ and an altitude between 220 and $1265 \mathrm{~m}$. This region is largely constituted by Tertiary volcanic rocks of the Coyol and Matagalpa groups (Fenzl, 1988). The Oligocenic Matagalpa group is composed of rhyolitic to dacitic pyroclastic rocks, whereas the Coyol group emplaced during Miocene-Pliocene period is made up of basaltic rocks, rhyolitic lavas, breccias, lahars and pyroclastic deposits (Darce et al., 1989; Ehrenborg, 1996). Most of these rocks are covered by a thick regolith and colluvial deposits.

The study area covers about $68 \mathrm{~km}^{2}$ and forms part of the municipalities of San Nicolás and Santa Rosa del Peñón in the Estelí and Leon Departments, respectively (Fig. 1). The first settlements were established approximately one century ago, and since then around $90 \%$ of what used to be thickly forested land has been converted into bush land, degraded pastures and agricultural fields. The settlements are scattered, and construction materials consist of adobe and wood. The economy is based on subsistence corn, bean and cereal agriculture, and to a lesser extent, on cattle. 


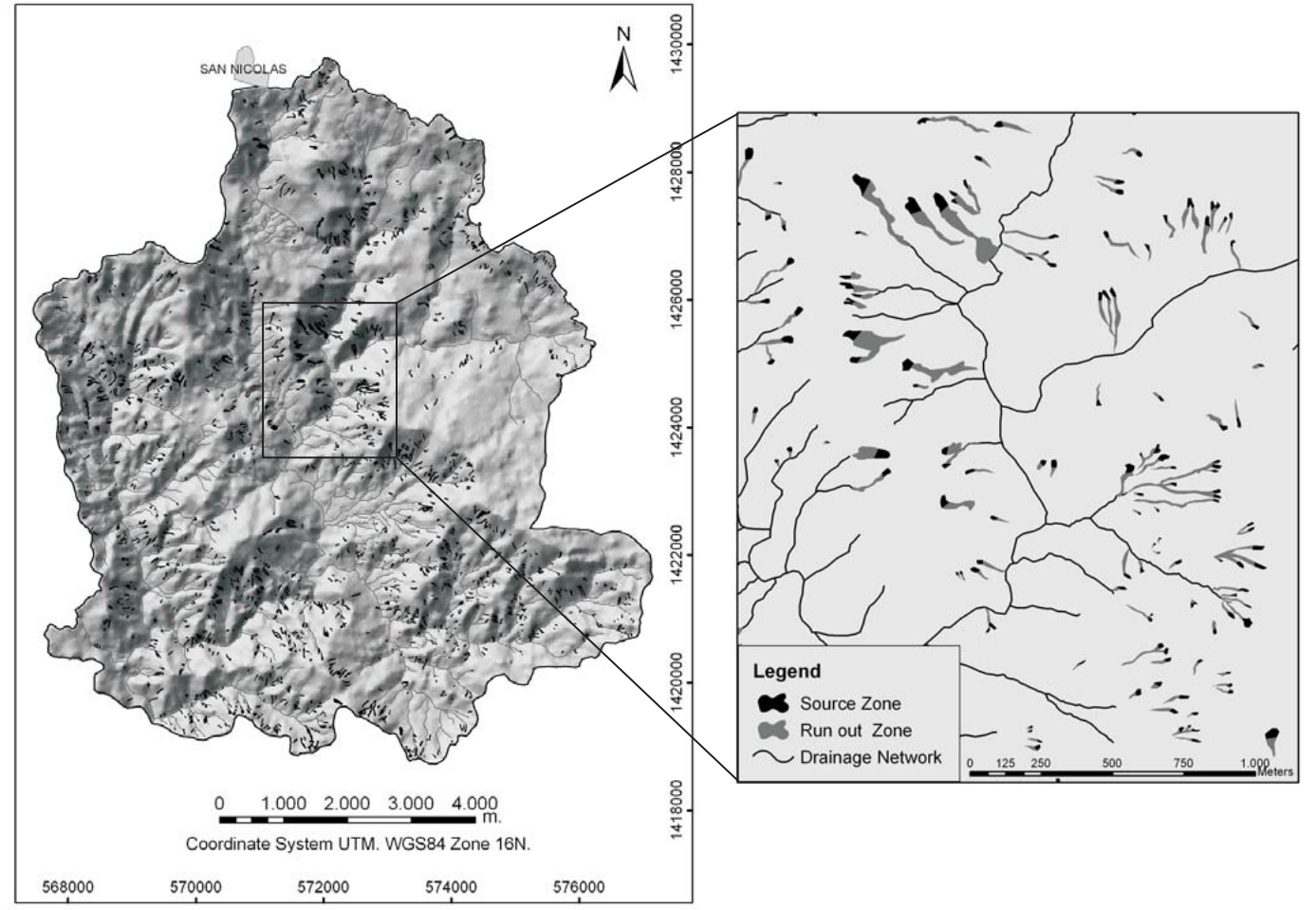

Fig. 2. Landslide map and an enlarged portion showing failure-zones (in dark grey) and the areas affected by the path or the deposition of mobilized material (in light grey).

The region has a tropical climate characterized by hurricanes and tropical storms, especially in the wet months, from September to November. Although the study area has been affected historically by these phenomena, the most catastrophic event was Hurricane Mitch in 1998. This hurricane caused floods and thousands of landslides, mainly debris flows, resulting in a high death toll and in considerable damage to property.

\section{Data acquisition}

Two types of data enable us to develop and validate the landslide source and runout susceptibility assessment in the study area: 1) a Digital Elevation Model obtained recently for the Pacific region in Nicaragua and 2) a landslide inventory and map produced specifically for this analysis.

\subsection{Digital Elevation Model}

A $20 \mathrm{~m} \times 20 \mathrm{~m}$ resolution DEM has been available in $15 \%$ of the Pacific Region of Nicaragua since August 2006. This model was generated from aerial photograph restitution and elevation control points in the frame of a project developed by INETER (Instituto Nicaragüense de Estudios Territoriales) in cooperation with JICA (Japan International Cooperation Agency).

\subsection{Landslide inventory and map}

The landslides triggered by Hurricane Mitch were catalogued and mapped to determine the mechanisms of landslides and the instability factors involved. A black and white aerial photograph set, taken in December 1998 (1 month after Hurricane Mitch), was available at 1:30000 scale in the study area (special flight made by United States Geological Survey). These photographs yielded an acceptable resolution and allowed a detailed interpretation. The landslides caused by Hurricane Mitch were mapped and transferred over orthophotos at 1:10000 scale, obtaining a preliminary landslide map. This map was checked and corrected in the field to obtain the definitive landslide map at 1:10 000 scale. Field observations were also made in the areas with most landslides to obtain information on the mechanisms and the instability factors involved in slope failure. $90 \%$ of the observed movements were shallow landslides controlled by groundwater flow convergence which quickly evolve to debris flow. The average rupture surface was $500 \mathrm{~m}^{2}$ and the debris volume mean was $2500 \mathrm{~m}^{3}$.

The resulting inventory and map were digitized in ArcInfoGIS software. In the landslide map the movements were systematically divided into the failure and the runout zones (Fig. 2). In order to carry out a joint analysis of landslides and DEM data, the failure zones were rasterized to the DEM 


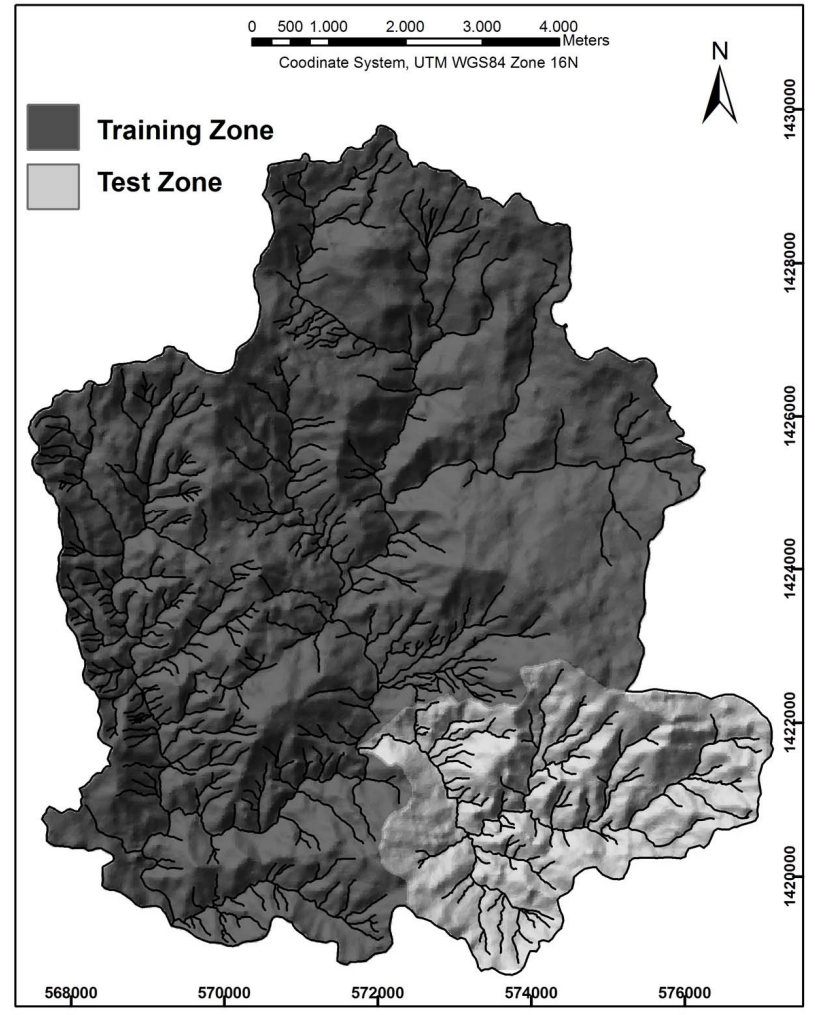

Fig. 3. Division of the study area into training zone (in dark grey) and test zone (in light grey).

resolution in ArcGIS. Each failure was assumed to be within a single $20 \mathrm{~m} \times 20 \mathrm{~m}$ pixel (Dai and Lee, 2002; Coe et al., 2004).

\section{Terrain failure susceptibility analysis}

Bivariate statistical procedure is the most simple and the most quantitatively suitable method to assess terrain failure susceptibility. This analysis makes use of simple statistical calculations, which allows us to determine the contribution of each terrain parameter to the slope instability obviating the need for experts in statistics or specific statistical package. Thus, it can be developed using common GIS tools. The aim of the bivariate method is to combine landslide map and conditioning factors, which exert an influence on slope instability, in order to determine the weight of influence for each factor class. These weights are added up to obtain the terrain failure susceptibility index. Although scientifically a continuous variable is more informative than a stored categorical scale, most of the final users will find that a map with susceptibility classes (i.e. low, medium and high susceptibility) is easier to handle than a cryptic numerical value (Chung and Fabbri, 2003; Begueria, 2006). Thus, the terrain failure susceptibility indexes are generally classified in intervals in order better visualize the terrain failure susceptibility zonation in a map.

Finally, it is of paramount importance to validate the model results. In this process the susceptibility map is compared with a failure population that is independent from the one used to obtain the map in order to determine the accuracy of the model. In the absence of historical data or of a landslide event after Hurricane Mitch, the same failure set should be used for validation. However, in order to obtain two independent failure samples the study area was divided into a training zone and a test zone (Fig. 3), following the approach of Baeza and Corominas (2001), Remondo et al. (2003b) Chung and Fabbri $(2003,2005)$ and Guinau et al. (2005).

\subsection{Selection, extraction and discretisation of instability factors from DEM}

In the absence of geoenvironmental maps showing parameters such as lithology, land use, regolith thickness, we proposed a susceptibility model using geometrical parameters extracted from DEM. It has been demonstrated that reliable susceptibility maps can be produced by using conditional parameters exclusively derived from a DEM (Remondo et al., 2003b; Fabbri et al., 2003; Santacana et al., 2003; Pallàs et al., 2004; Coe et al., 2004).

To determine the factors that contribute most to terrain instability, we considered field data and those parameters that could be directly extracted from DEM. Thus, Aspect, Slope, Planar Curvature (degree of concavity/convexity along a line perpendicular to slope profile) and Profile Curvature (degree of concavity/convexity of the slope profile) were obtained by using the 3D-Spatial Analyst module of ArcInfoGIS software (Moore et al., 1991; Ayalev et al., 2004; Coe et al., 2004). These parameters were selected due to its influence on soil water content, which is the responsible of landslides under heavy rainfalls. These continuous variables had to be converted into discrete ones in order to be incorporated at the bivariate analysis. Discretization was developed by using the Equal Interval process for aspect and slope and the Natural Breaks process for both planar and profile curvature (Dai and Lee, 2002). In Fig. 4 we can observe the thematic maps in which the discretized geometric parameters are represented. For Planar Curvature negative values show that the surface is upwardly concave and positive values indicate that the surface is upwardly convex. For profile curvature, negative values indicate that the surface is upwardly convex and positive values show that the surface is upwardly concave. A curvature value of zero indicates that the surface is flat for both planar and profile curvatures. Table 1 shows the percentage of the total study area covered by each class of the four parameters considered in the analysis. 

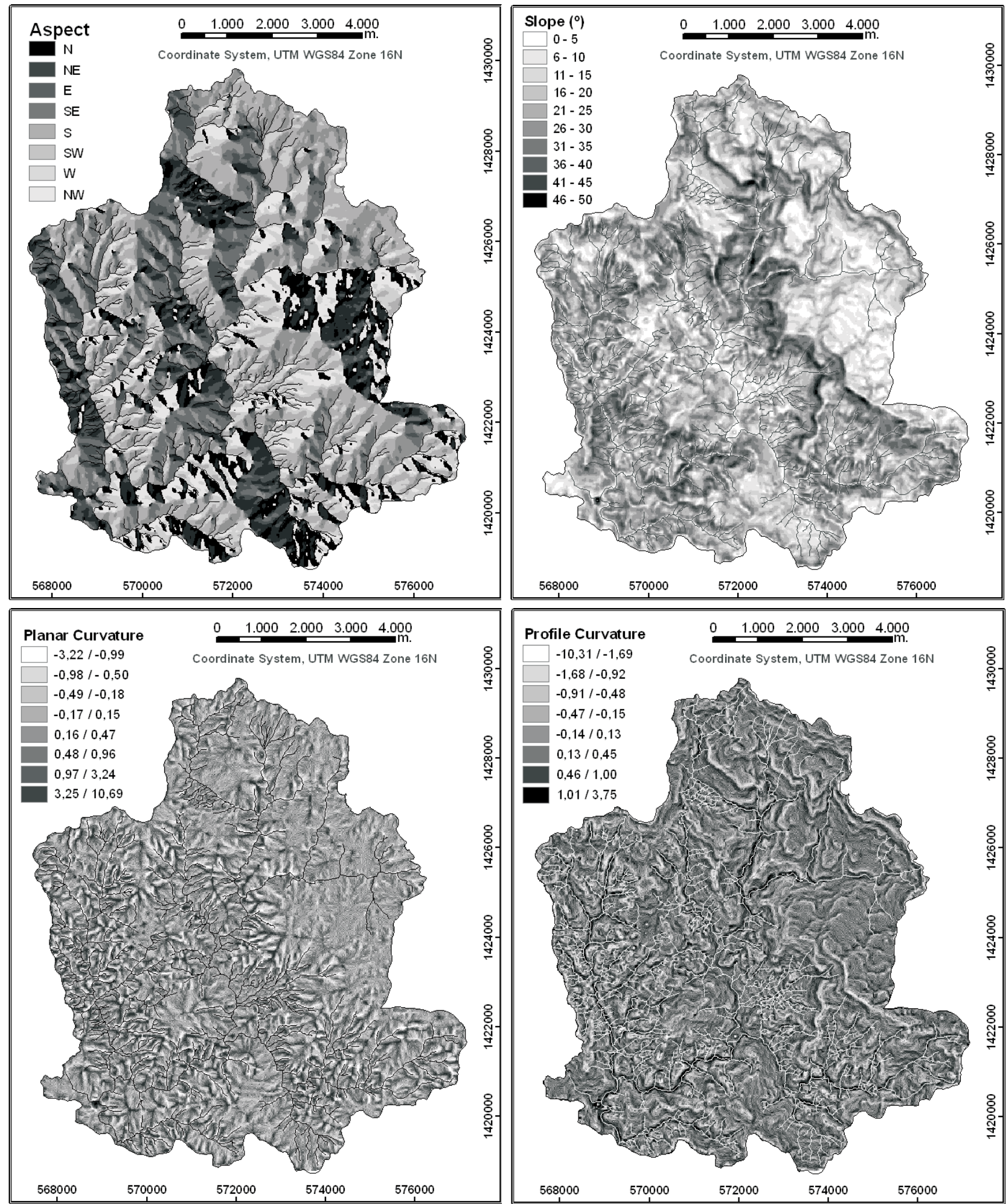

Fig. 4. Thematic maps obtained from the DEM. Each one shows a terrain factor defined by a given number of classes; (from left up to right down) Aspect, Slope, Planar Curvature and Profile Curvature. 
Table 1. Percentage of the total study area covered by each parameter class.

\begin{tabular}{cccccccc}
\hline Aspect & $\%$ Area & Slope $\left.^{\circ}\right)$ & $\%$ Area & Planar Curvature & $\%$ Area & Profile Curvature & $\%$ Area \\
\hline N & 9 & $0-5$ & 7 & $-3.22 /-0.99$ & 3 & $-10.31 /-1.69$ & 0 \\
NE & 10 & $6-10$ & 14 & $-0.98 /-0.50$ & 8 & $-1.68 /-0.92$ & 3 \\
E & 10 & $11-15$ & 17 & $-0.49 /-0.18$ & 21 & $-0.91 /-0.48$ & 9 \\
SE & 12 & $16-20$ & 20 & $-0.17 / 0.15$ & 31 & $-0.47 /-0.15$ & 21 \\
S & 15 & $21-25$ & 19 & $0.16 / 0.47$ & 23 & $-0.14 / 0.13$ & 28 \\
SW & 19 & $26-30$ & 14 & $0.48 / 0.96$ & 12 & $0.14 / 0.45$ & 25 \\
W & 14 & $31-35$ & 7 & $0.97 / 3.24$ & 3 & $0.46 / 1.00$ & 12 \\
NW & 11 & $36-40$ & 2 & $3.25 / 10.69$ & 0 & $1.01 / 3.75$ & 3 \\
& & $41-45$ & 0 & & & & \\
\end{tabular}

3.2 Terrain failure susceptibility analysis in the training zone

Van Westen (1993) and Saha et al. (2005) propose the Information Value (InfoVal) method developed by Yin and Yan (1988) for terrain failure susceptibility assessment. In this procedure combining the failure map with each thematic map in the training zone allows us to determine the weight of influence on terrain instability for each parameter class with the following equation $W_{i}$ (Eq. 1);

$W_{i}=\log ($ Densclass $/$ Densmap $)=$

$\log \left[\left(\operatorname{Npix}\left(S_{i}\right) / \operatorname{Npix}\left(N_{i}\right)\right) /\left(\sum_{i=1}^{n} \operatorname{Npix}\left(S_{i}\right) / \sum_{i=1}^{n} \operatorname{Npix}\left(N_{i}\right)\right)\right]$

Where $W_{i}$ is the weight for the $i$ th class of a particular thematic map (i.e. $0^{\circ}-10^{\circ}$ or $20^{\circ}-30^{\circ}$ in the thematic map "Slope"), Densclass is the failure density in the factor class, Densmap is the failure density within the whole study area, $\operatorname{Npix}\left(S_{i}\right)$ is the number of failed pixels in the $i$ th factor class, $\operatorname{Npix}\left(N_{i}\right)$ is the number of pixels in the $i$ th factor class, and $n$ is the number of classes in the thematic map.

Figure 5 shows the Information Value obtained for each parameter class. In the slope graph, it can be observed that slopes between $25^{\circ}$ to $45^{\circ}$ have the higher information values. The irregular distribution of the information values for slope aspect classes could indicate that this factor is not relevant in terrain instability. For planar and profile curvature the higher information values were obtained in zones with high convexity, whereas the concave zones had the lower information values. These could be explained because the high water infiltration in concave zones exerts an increase of pore water pressure in downslope convex zones, which contribute in terrain instability.

Once the Information Value for each variable class was calculated for all the input maps, the thematic maps were superimposed. The Information Values in each pixel were added in order to obtain a terrain failure susceptibility index (TFSI), which defines its landslide susceptibility level.
3.3 Terrain failure susceptibility discretization and validation in the test zone

In order to test this model, the weights determined for each factor class in the training zone were integrated into the thematic maps in the test zone. Terrain failure susceptibility indexes in this area were obtained by adding up the corresponding weights in each pixel.

The validation process allowed us to determine the degree of confidence of the method, which is important for transferring the results to the final users (Remondo et al., 2003a, b; Chung and Fabbri, 2003; Beguería, 2006; Guzzetti et al., 2006). The validation of the model also helps to define its suitability for the needs of the end users, which often involves terrain zonation in different susceptibility levels. Thus, the cumulative percentage of failures in the test zone in relation to the terrain failure susceptibility indexes (TFSI) (Fig. 6) was used to define susceptibility classes. Four susceptibility classes were defined as follows; very low susceptibility $(-197<$ TFSI $>-153$, interval containing $0 \%$ of failures); low susceptibility $(-152<$ TFSI $>-31$, interval containing $10 \%$ of failures); medium susceptibility $(-30<$ TFSI $>19$, interval containing $30 \%$ of failures $)$ and high susceptibility $(20<$ TFSI $>90$, interval containing $60 \%$ of failures) (Süzen and Doyuran, 2004). These thresholds were used for the terrain failure susceptibility zonation in the whole study area.

In order to validate the accuracy of the model, the terrain failure susceptibility map was compared with the failure map in the test zone. A relative failure density (RFD) was used to quantify the accuracy of the method (Eq. 2) (Duque et al., 1990; Baeza and Corominas, 2001; Santacana et al., 2003; Fernández et al., 2003; Remondo et al., 2003b; Chung and Fabbri, 2003, 2005; Guinau et al., 2005).

$\operatorname{RFD}_{i}=100 \cdot\left(\operatorname{Npix}\left(S_{i}\right) / \operatorname{Npix}\left(N_{i}\right)\right) / \sum_{i=1}^{n}\left(\operatorname{Npix}\left(S_{i}\right) / \operatorname{Npix}\left(N_{i}\right)\right)$

Where $\operatorname{Npix}\left(S_{i}\right)$ is the number of pixels failed in the $i$ th susceptibility class, $\operatorname{Npix}\left(N_{i}\right)$ is the number of pixels in the 

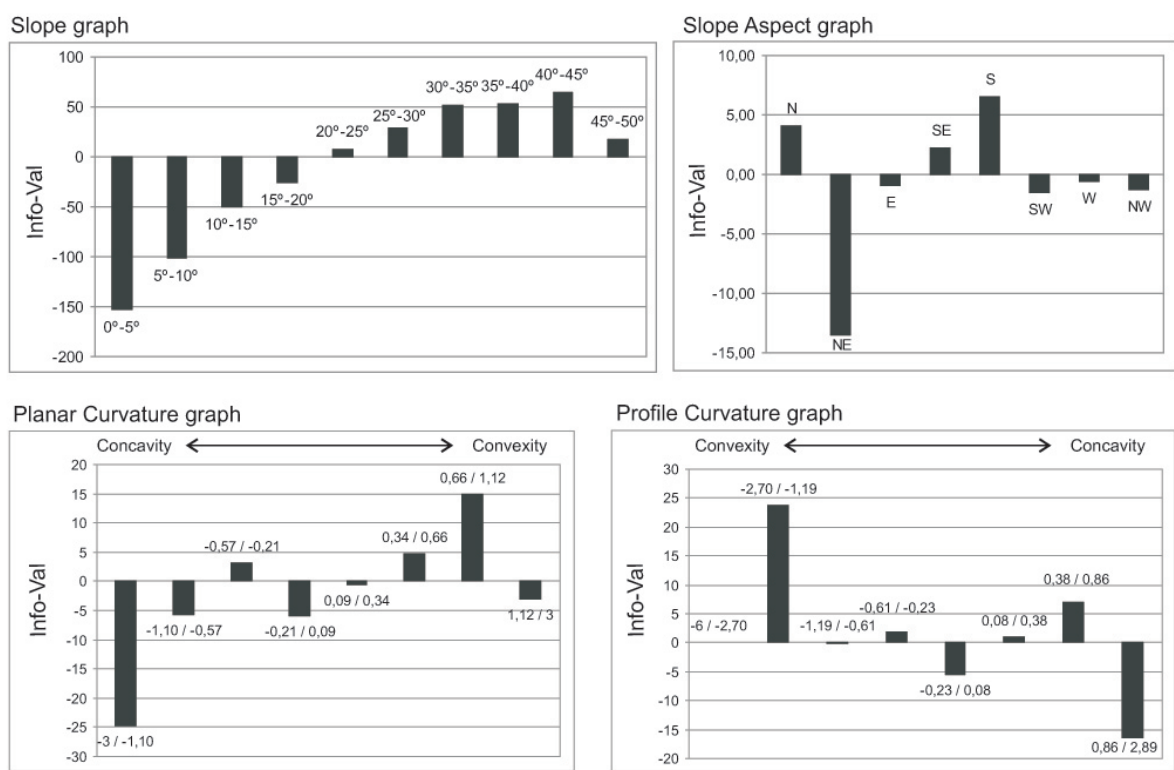

Fig. 5. Graphics showing the information values obtained for each contributing factor in the training zone.

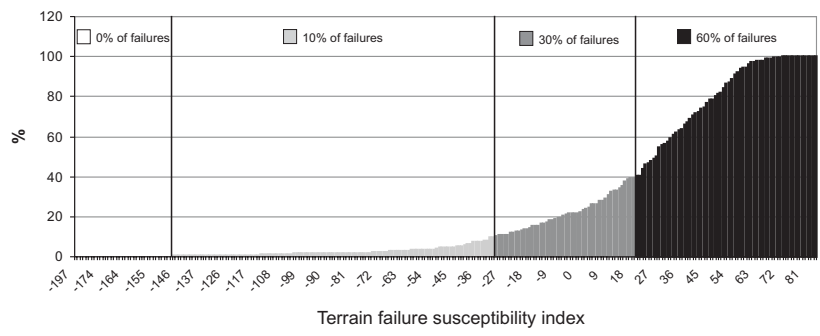

Fig. 6. Graphic showing the cumulative percentage of failures versus the terrain failure susceptibility index (TFSI). The intervals used to define the susceptibility classes are marked in different grey tones: In white the range containing $0 \%$ of failures, in light grey the range containing $10 \%$ of failures, in dark grey the range containing $30 \%$ of failures and in black the range containing $60 \%$ of failures.

$i$ th susceptibility class and $n$ is the number of susceptibility classes. Figure 7 a shows the relative failure density in each susceptibility class resulting in a gradual decrease in the relative landslide density between the areas with high susceptibility and the areas with low susceptibility. The percentage of area covered by each susceptibility class is indicated in Fig. 7b. Although this finding shows that the model is a good fit, it does not demonstrate its predictive capability. A set of failures triggered in a time period different from the one used in the analysis is necessary in order to determine this predictive capability.

Figure 8 shows the terrain failure susceptibility zonation in the whole study area, where; $8 \%$ has very low susceptibility, $34 \%$ has low susceptibility, $37 \%$ has medium susceptibility and $21 \%$ has high susceptibility.

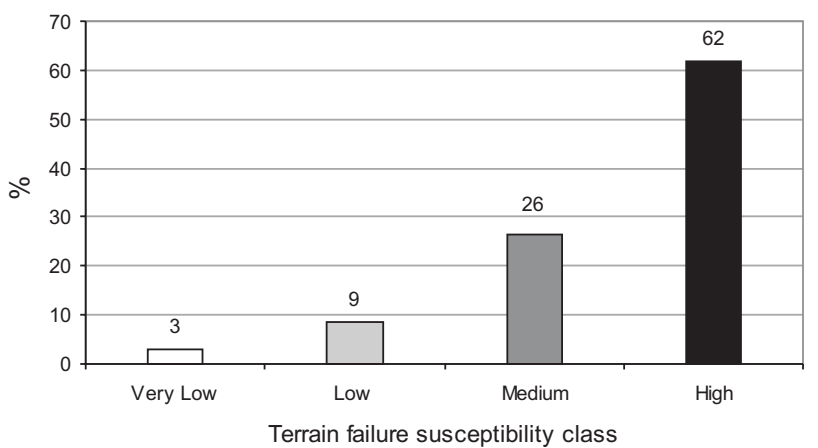

Fig. 7a. Graphic showing the relative failure density (RFD) for each terrain failure susceptibility class.

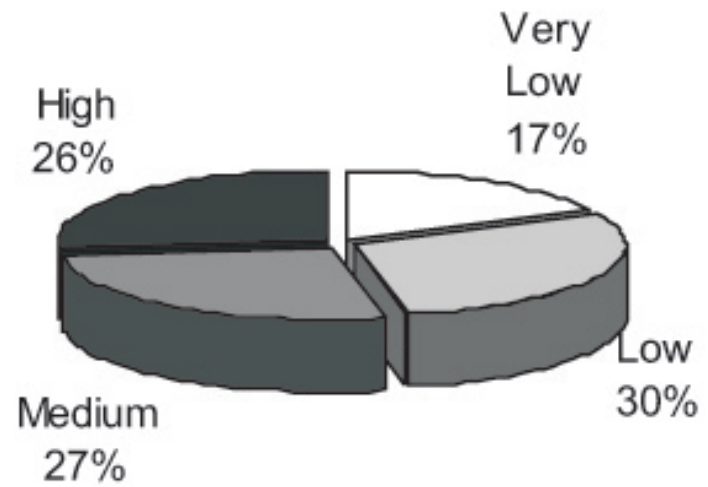

Fig. 7b. Percentage of area occupied by each susceptibility class in the test zone. 


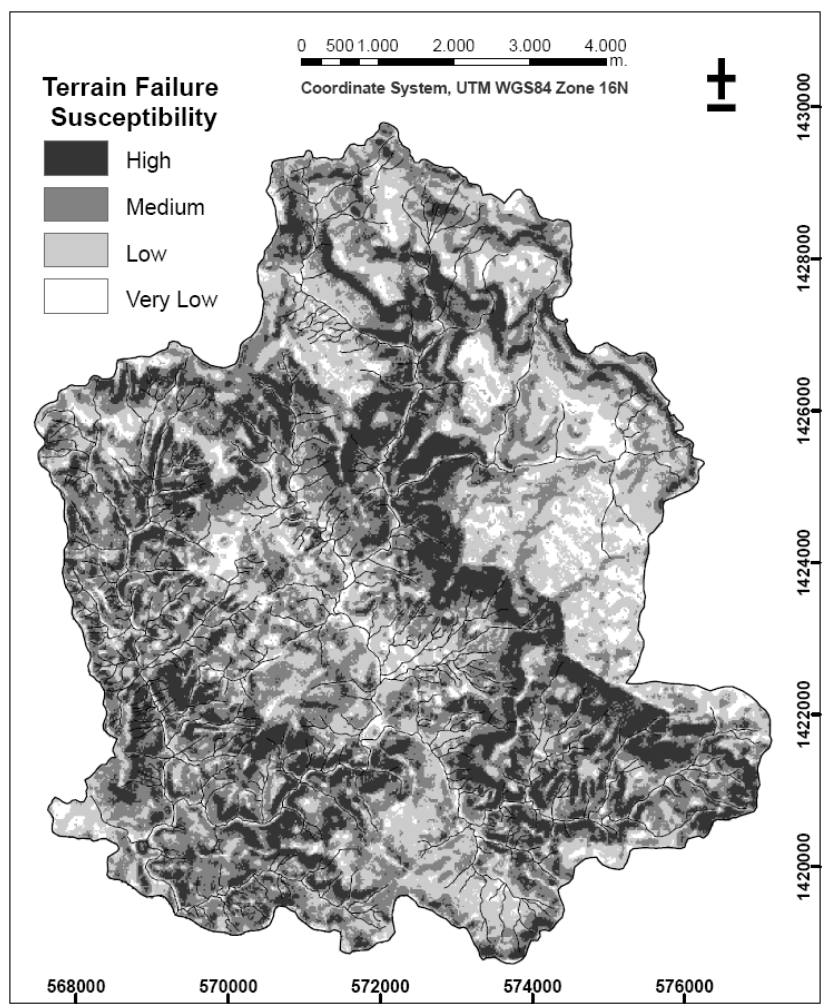

Fig. 8. Terrain failure susceptibility map obtained for the whole study area.

\section{Runout susceptibility analysis using TauDEM tools}

Runout behaviour can be controlled by several parameters such as topography, soil type, land use, debris volume and the amount of interstitial fluids. Given the difficulty of characterizing these parameters for future debris flows, it is not easy to determine the runout path and the reach distance. However, this problem can be overcome by taking into account the fact that under intense rainfall debris flows tend to travel long distances following the steepest path and merging with the drainage network (Montgomery and Dietrich, 1994; Pallàs et al., 2004; Guinau et al., 2005). In order to determine the areas that are prone to debris flow, we propose a methodology based on the use of the open source TauDEM software developed by Tarboton (1997), which is available electronically on the Internet from the author (dtarb@cc.usu.edu, http://www.engineering.usu.edu/dtarb/taudem).

\subsection{TauDEM tools description}

TauDEM is software that can be executed as an ArcGIS extension. This software contains a set of tools which facilitate the assessment of hydrologic processes from DEM. In this study, two of these tools were used: the flow direction $(D \infty)$ and the downslope influence (DI). The former is used to assign a multiple number of possible flow directions to each pixel based on the direction of the steepest downwards slope (Tarboton, 1997). The latter is employed to track the movement of sediment from a given source pixel, taking into account the flow direction in each downslope pixel (Tarboton, 1997).

\subsection{Model calibration}

The model was calibrated to determine its adjustment with the debris flow behaviour in the study area. This enabled us to compare the model results with a known event (in this case the landslides triggered by Hurricane Mitch resulting in debris flows corresponding to $90 \%$ of the total landslides mapped in the study area). The DI tool was used to delineate potential debris flow tracks downslope from mapped landslide initiation locations as indicated by flow direction inferred from the DEM. In this way the model calculates the flow concentration for each pixel from the source point to the drainage network, where the flow concentration is the highest. Thus, the highest DI values coincide with the drainage network.

A comparison between the modelled flow paths and the Hurricane Mitch debris tracks shows that this method overestimates the area affected by debris flow runout (Fig. 9). The relative runout density was calculated to quantify this deviation (Eq. 3).

$\operatorname{RRD}_{i}=100 \cdot\left(A\left(S_{i}\right) / A\left(D I_{i}\right)\right) / \sum_{i=1}^{n}\left(A\left(S_{i}\right) / A\left(D I_{i}\right)\right)$

Where $A\left(S_{i}\right)$ is the area affected by debris flow track in the $i$ th ID interval, $A\left(\mathrm{DI}_{i}\right)$ is the area of the $i$ th ID interval and $n$ is the number of ID intervals.

Figure 10 shows that when DI values encompass about $90 \%$ of all mapped debris flow runout zones. As shown in Fig. 11, excluding areas with $\mathrm{DI}<0.05$ substantially reduces the areas delineated with the DI tool.

\subsection{Runout susceptibility assessment}

Terrain failure susceptibility classes were used in this case as source zones to assess the runout susceptibility in the study area. Each terrain failure susceptibility class was divided into an independent raster file where the pixels susceptible to failure were identified by 1 and the others by 0 . Each raster file was processed independently to determine the downslope influence for each susceptibility class. Given the results of the model calibration, the pixels were reclassified as runout susceptible if $\mathrm{DI} \geq 0.05$ or non susceptible if $\mathrm{DI}<0.05$. For each resulting file the runout susceptible pixels were identified by a number. The size of this number depended on whether the field was obtained from terrain failure susceptibility high (value assigned 4), medium (value assigned 3), low (value assigned 2) or very low (value assigned 1) (Fig. 12). Finally, the four resulting files were combined bearing in mind that the highest susceptibility value prevailed in each pixel. This 


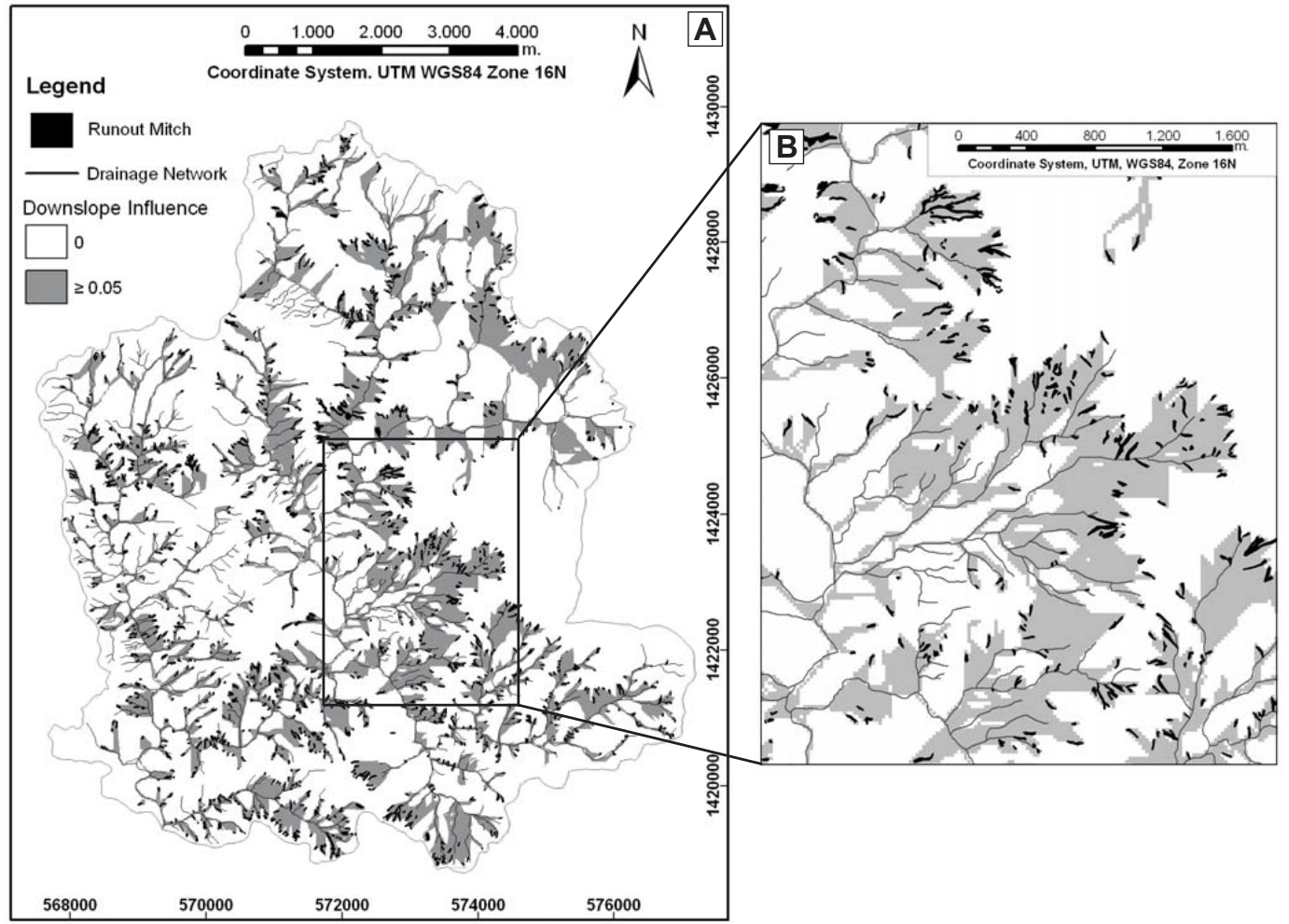

Fig. 9. (a) Map showing the downslope influence obtained from the terrain failures triggered by Hurricane Mitch in grey tones and the Hurricane Mitch runout areas in black. (b) An enlarged area of this map showing the overestimation of the model.

resulted in a runout susceptibility map in which the pixels were classified into four susceptibility classes (Fig. 12).

\subsection{Runout susceptibility map: description and validation.}

Figure 13 shows the runout susceptibility zonation in the whole study area, where $3 \%$ has very low susceptibility, $13 \%$ has low susceptibility, $28 \%$ has medium susceptibility and $56 \%$ has high susceptibility. In order to validate the accuracy of the model, this zonation is compared with the Hurricane Mitch runout areas and the relative runout density (RRD) is calculated for each runout susceptibility class (Eq. 4).

$\mathrm{RRD}_{i}=100 \cdot\left(A\left(S_{i}\right) / A\left(N_{i}\right)\right) / \sum_{i=1}^{n}\left(A\left(S_{i}\right) / A\left(N_{i}\right)\right)$

Where $A\left(S_{i}\right)$ is the area affected by debris flow track in the $i$ th susceptibility class, $A\left(N_{i}\right)$ is the area of the $i$ th susceptibility class and $n$ is the number of susceptibility classes.

Figure 14 shows a higher concentration of affected areas in zones with high susceptibility.

\section{Source and runout susceptibility integration}

Two concepts were used to assess landslide susceptibility: a) the terrain failure susceptibility and $b$ ) the runout susceptibil-

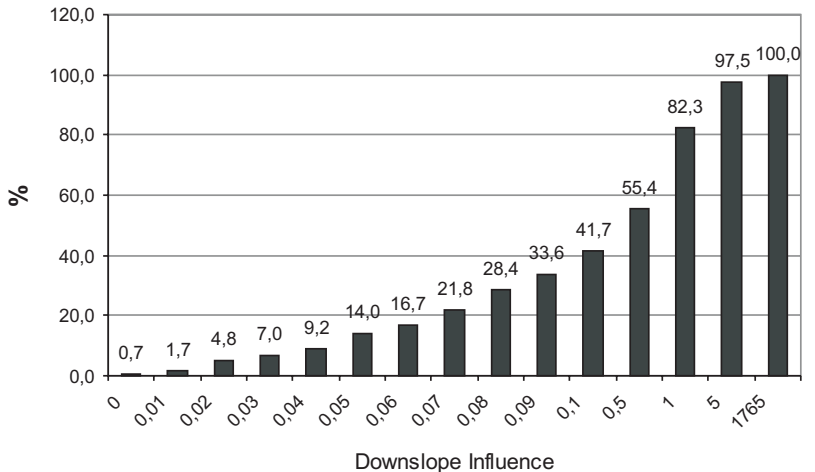

Fig. 10. Graphic showing the accumulated relative runout density (RRD) in \% versus the Downslope Influence (DI) values.

ity. The combination of these concepts yields an integrated susceptibility zonation which can be useful for land planning or for the implementation of non structural measures to mitigate debris flow risk.

To obtain an integrated evaluation of the susceptibility, we used a matrix to combine the terrain failure susceptibility classes and the runout susceptibility classes (Fig. 15). These combinations were grouped into four susceptibility 


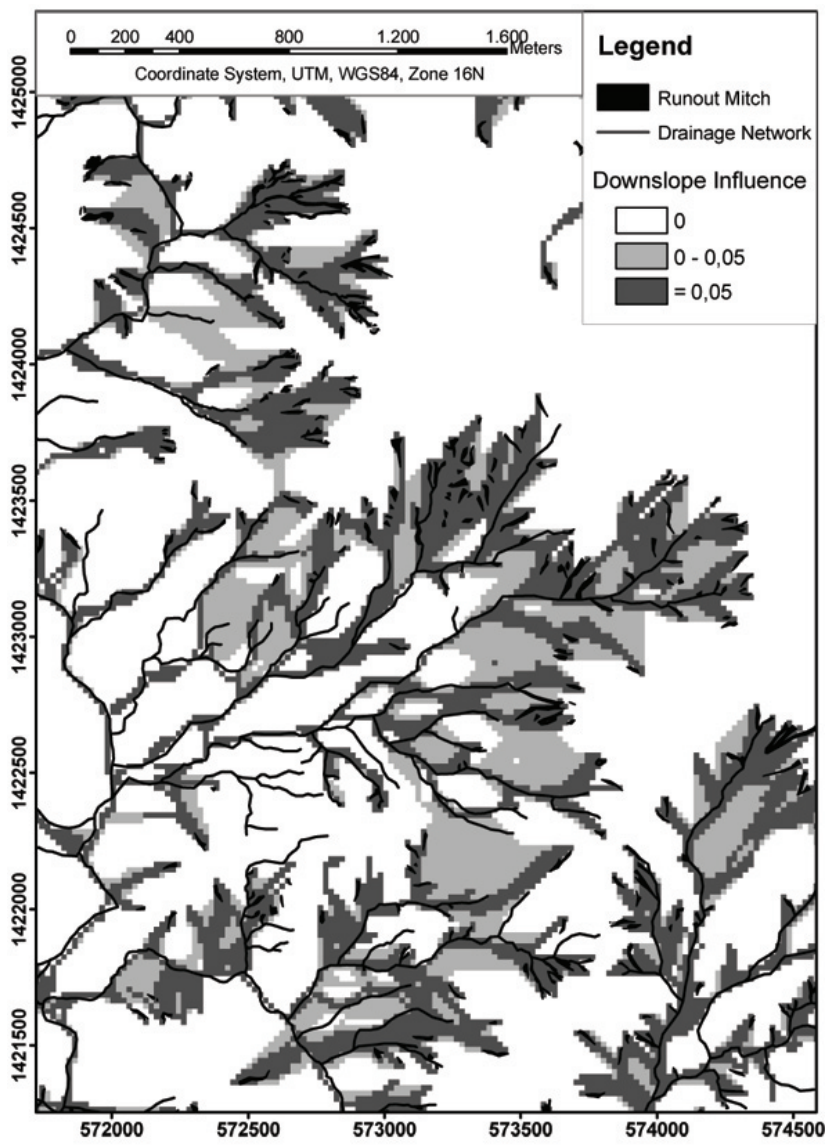

Fig. 11. The same enlarged area of Fig. 8 where the DI values are showed in 3 classes; DI $=0$ in white, $0<\mathrm{DI}<0.05$ in light grey and $\mathrm{DI} \geq 0.05$ in dark grey. Note that Hurricane Mitch affected areas (in black) are concentrated inside the area with $\mathrm{DI} \geq 0.05$.

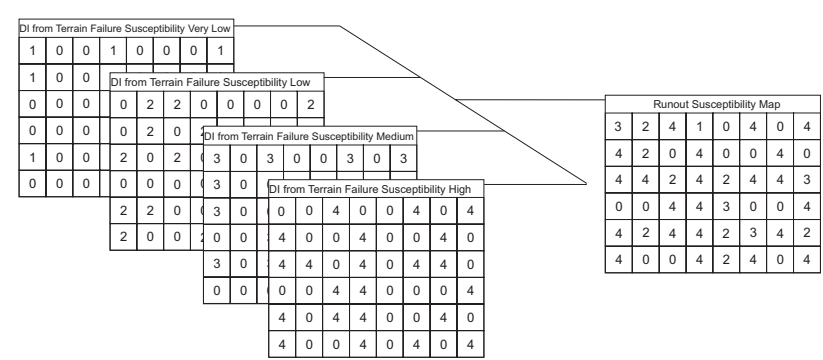

Fig. 12. A graphic example of the four raster files obtained after modelling the flow paths from each terrain failure susceptibility map. In each file the pixels that are non susceptible to debris flow were identified with zero and the pixels that are susceptible with a different value ( 1 to 4 ). The combination of these files enables to obtain the runout susceptibility map where the pixels were reclassified in four susceptibility classes.

classes considering that the weight of failure susceptibility was higher than that of runout susceptibility, given that the debris track depends on the slope failure occurrence. Thus,

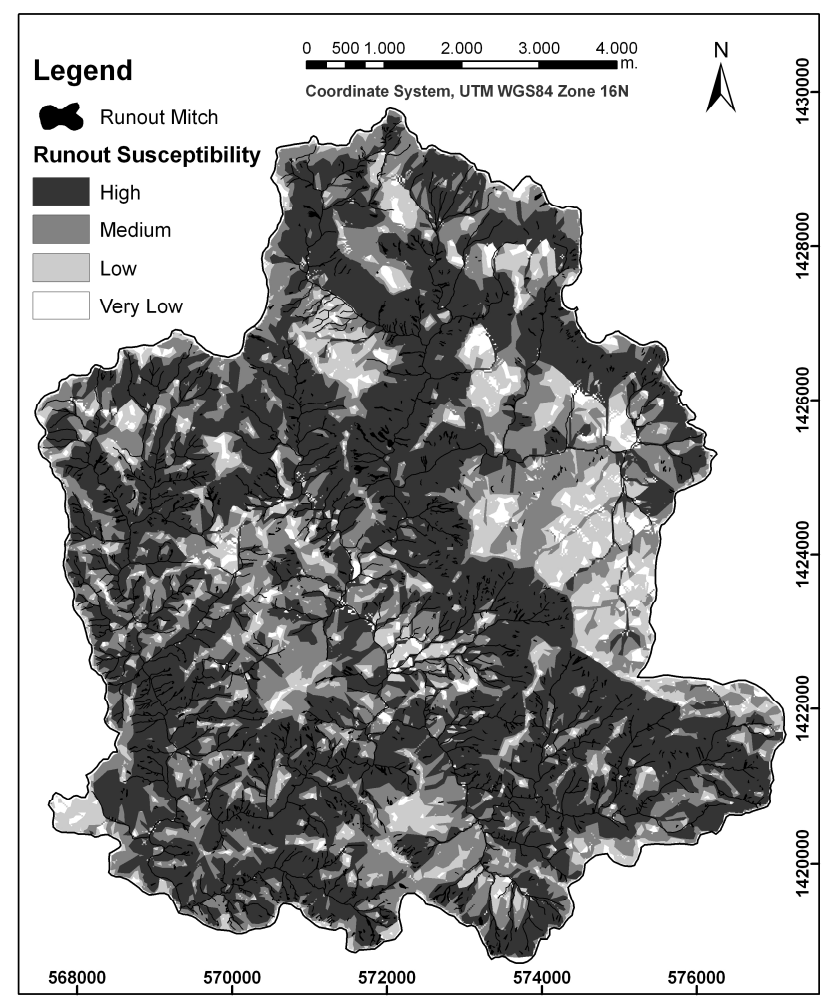

Fig. 13. Runout susceptibility map obtained in the whole study area.

each pixel had a susceptibility class in relation to its terrain failure and runout susceptibility class. This result is shown in the debris flow susceptibility map in Fig. 16, where $41 \%$ of the study area has high susceptibility, $40 \%$ has medium susceptibility, $16 \%$ has low susceptibility and $3 \%$ has very low susceptibility. This map was compared with the debris flows triggered by Hurricane Mitch to determine the significance of each susceptibility class for land planning. Figure 17 shows the relative debris flow density measured for each susceptibility class. These results can help us to determine the best land use for debris flow risk mitigation.

\section{Discussion and conclusions}

Landslides triggered by Hurricane Mitch are used in the present study to develop a methodology to assess and map landslide source and runout susceptibility. Therefore, the resulting susceptibility maps show areas that may be affected by landslides under heavy rainfall conditions. Given that the return period for Hurricane Mitch rainfall is estimated at around 100 years (INETER, 1998), the resulting susceptibility zonation would be excessively pessimistic. However, adopting the worst-scenario approach has the advantage of providing a degree of safety.

The principal drawback of the method used to assess terrain failure susceptibility (bivariate analysis) is that it 


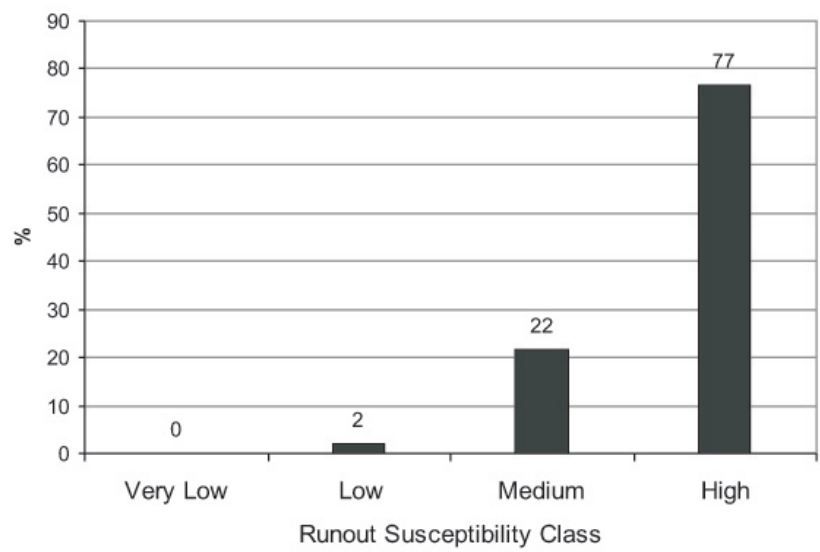

Fig. 14. Graphic showing the relative runout density (RRD) in $\%$ for each runout susceptibility class obtained from the combination of the Hurricane Mitch runout areas and the runout susceptibility map.

\begin{tabular}{|c|c|c|c|c|}
\hline $\begin{array}{c}\text { Failure } \\
\text { Runout } \\
\text { Susceptibility }\end{array}$ & $\begin{array}{c}\text { High } \\
\mathrm{H}\end{array}$ & $\begin{array}{c}\text { Medium } \\
\mathrm{M}\end{array}$ & $\begin{array}{c}\text { Low } \\
\text { L }\end{array}$ & $\begin{array}{c}\text { Very Low } \\
\text { VL }\end{array}$ \\
\hline $\begin{array}{c}\text { High } \\
\mathrm{h}\end{array}$ & $\mathrm{Hh}$ & $\mathrm{Mh}$ & $\mathrm{Lh}$ & VLh \\
\hline $\begin{array}{c}\text { Medium } \\
\mathrm{m}\end{array}$ & $\mathrm{Hm}$ & $\mathrm{Mm}$ & $\mathrm{Lm}$ & VLm \\
\hline $\begin{array}{c}\text { Low } \\
\mathrm{I}\end{array}$ & $\mathrm{HI}$ & $\mathrm{Ml}$ & $\mathrm{LI}$ & $\mathrm{VLI}$ \\
\hline $\begin{array}{c}\text { Very Low } \\
\text { Vl }\end{array}$ & $\mathrm{Hvl}$ & $\mathrm{Mvl}$ & LVI & VLVI \\
\hline
\end{tabular}

Fig. 15. Matrix where the terrain failure susceptibility class on the columns and the runout susceptibility class on the rows were combined in order to define four susceptibility classes for the final susceptibility zonation. In white susceptibility very low, in light grey susceptibility low, in dark grey medium susceptibility and in black high susceptibility.

assumes the independence of the different terrain parameters with respect to slope instability. However, the most realistic approaches consider the dependence of the conditioning factors. Some authors overcome the problem by combining the dependent factors in a land unit map and by assessing the landslide susceptibility from this map (Carrara et al., 1995; van Westen et al., 1997). This approach assumes that the instability factors remain the same in the whole study area. In the absence of common factors in the study area, some land units could be present in one zone (i.e. the training area) but not in another (i.e. the test area), which makes the validation process difficult or even impossible (Guzzetti et al., 2006).

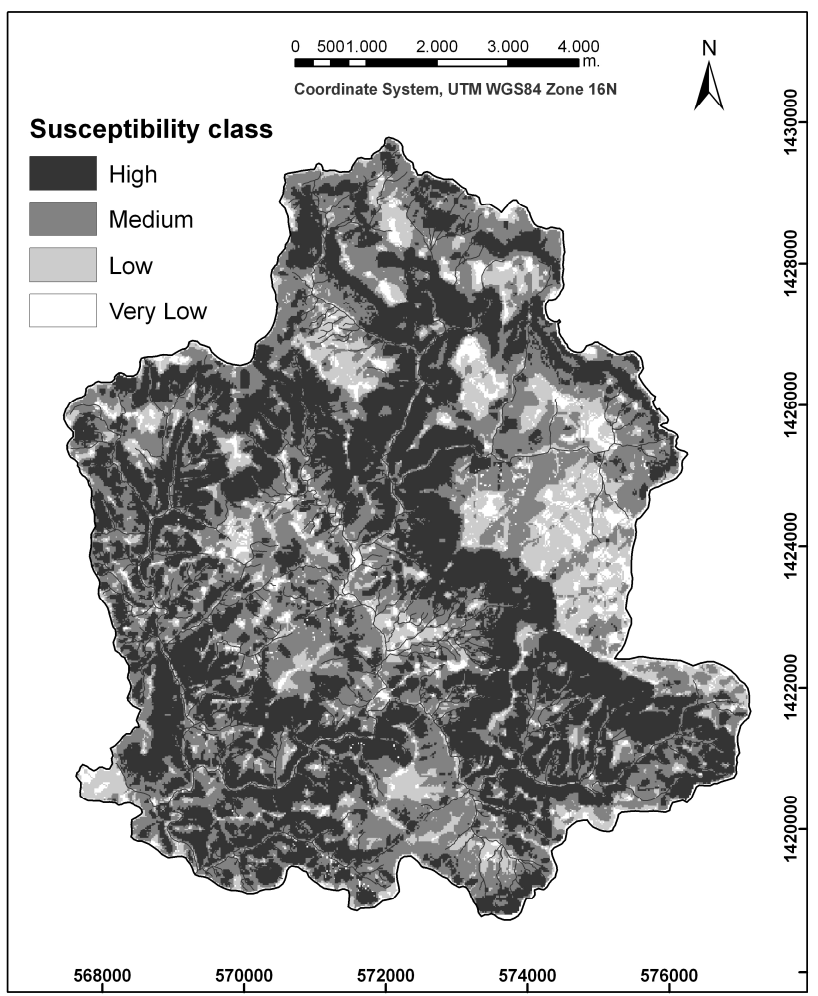

Fig. 16. Landslide susceptibility map obtained after terrain failure susceptibility and runout susceptibility integration.

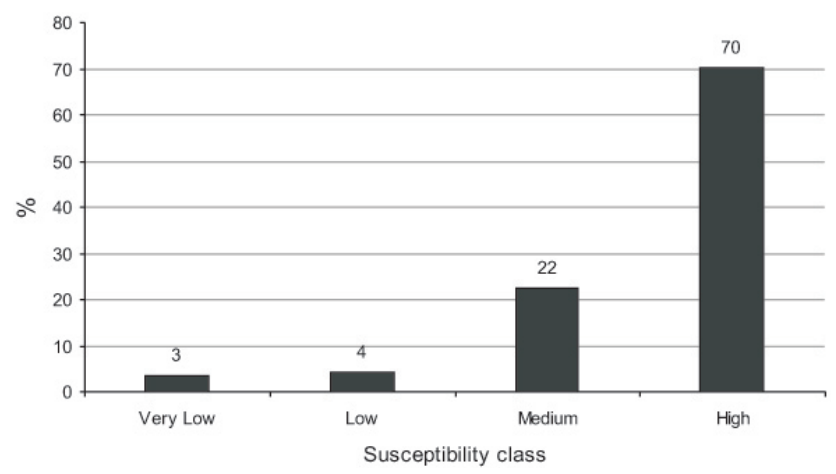

Fig. 17. Graphic showing the relative landslide density (in \%) for each susceptibility class obtained from the combination of landslides triggered by Hurricane Mitch, and the final susceptibility map.

Although multivariate statistical methods consider various parameters simultaneously, they demand complex and timeconsuming analyses and a statistical background, which is not suitable for the conditions in some developing countries. Thus, the bivariate method is the most helpful in obtaining terrain failure susceptibility maps that differentiate areas of increasing degrees of susceptibility. This is a reasonable approach to hazard assessment given that the resources in developing countries are limited. 
One problem encountered in the study area when assessing landslide susceptibility is the lack of detailed information about bedrock, soil and geomoprhologic characteristics. However, lithology and land cover are relatively uniform with slopes covered by a regolith cloak of volcanic rocks and thin vegetation which exert a homogeneous influence on terrain instability (Parise and Jibson, 2000; Baeza and Corominas, 2001; Ayalew et al., 2005). Moreover, geoenvironmental variables are not independent from geometrical ones, i.e. slope is closely related to bedrock and land use could be conditioned by slope gradient. Thus, if both geoenvironmental and geometrical parameters are considered in the analysis, an overestimation of the susceptibility could result (Remondo et al., 2003a). Operations with the GIS enable us to readily obtain geometrical parameters from DEM. Four of these parameters (slope, aspect, planar and profile curvature) were selected to develop the terrain failure susceptibility analysis given that they affect water infiltration. Thus, they are contributing factors in rainfall triggered landslides in the study area. The weights of influence obtained in the terrain failure susceptibility analysis (Fig. 5) show a clear influence of the slopes between $25^{\circ}$ and $45^{\circ}$ in terrain instability. Whereas the information values obtained for both planar and profile curvature shows a clear contribution of zones with high convexity. The information values for the slope aspect don't follow a clear distribution. Thus, the contribution of this factor could be less relevant than the slope and curvature ones.

DEM resolution exerts a considerable influence on the accuracy of the derived parameters. Although a coarse DEM resolution could be of poor quality in some cases, the gain in the quality of the results would not be worth the efforts (Remondo, et al., 2003b). Given the dimensions of the shallow landslide and debris flows in the study area, a $10 \mathrm{~m} \times 10 \mathrm{~m}$ DEM could be optimal for analysing the landslide source and runout susceptibility (Tarolli and Tarboton, 2006). However, the results obtained with the $20 \mathrm{~m} \times 20 \mathrm{~m}$ DEM available in the study area could constitute a good approach to failure and runout prone areas.

Debris flow is a complex phenomenon involving a highly unsteady motion of heterogeneous material ranging from water and slurries to boulders and timber remains. Debris flow mobility depends on parameters such as debris volume, the amount of interstitial fluids and terrain morphology. The assessment of flow velocities or impact energy to determine runout path and distance is not easy owing to the difficulty of determining these parameters for future debris flows. The methodology proposed to determine areas potentially affected by a debris flow path was based on DEM. The TauDEM extension allowed us to determine the flow paths following the steepest tracks from the potential source areas to the drainage network. However, the flow paths observed in the study area do not always merge with the drainage network with the result that the model overestimates the area that is potentially affected by debris flows. Many authors have pointed out empirical relations between runout extent and other attributes readily calculated from a DEM, such as the ratio $H / L$ (where $H$ is the vertical drop and $L$ is the horizontal projection of the distance) (Corominas, 1996; Bathurst et al., 1997; Rickenmann, 1999). Although, the methodology based on the use of TauDEM tools is a good starting point to determine potential flow paths, it could be complemented with a method to determine the runout extend in order to improve the ability of the model to resolve debris flow susceptible areas.

The model calibration process allows us to determine a downslope influence threshold to adjust the model results to the debris flow behaviour. This process improves the model results. It should also be pointed out that the DEM resolution and the data available are not the best means to obtain a model adjusted to the debris flow behaviour. However, this model is a good way to determine areas prone to debris flows, and can be helpful in some developing countries to mitigate debris flow risk.

The validation of the model can provide useful information to build up the confidence of the end users. Despite the limitations of the validation process based on the division of the study area, it is a good approach in those areas where only one reference event is available. However, this process only provides information about how the model fits and not about the predictability power of the maps obtained. The validation results suggest that a careful selection of geometrical parameters from DEM and the application of feasible functions to calculate the parameter class contribution to terrain instability enable the detection of potential debris flow source areas. In the case of the runout susceptibility analysis, the validation results show a good model fit. However, the extension of high and medium susceptibilities occupy a considerable area (56\% and $28 \%$ respectively), which could be disadvantageous for land planning or policy makers. These results are reflected in the susceptibility map obtained with the integration of terrain failure and runout susceptibility. In the debris flow susceptibility map (Fig. 16) $41 \%$ and $40 \%$ of the study area have high and medium susceptibilities, respectively. These results could be expected given the land characteristics of the study area (drainage network largely incised in altered bedrock and high slopes). Although the susceptibility zonation does not seem very precise, it is possible to propose land planning rules to mitigate landslide risk. Given that the economy is based on subsistence agriculture and that the settlements are scattered, a forested land use is proposed for areas with high susceptibility and agricultural activities for areas with medium susceptibility. The areas with low and very low susceptibility (16\% and 3\% respectively) are reserved for settlements, schools and churches. These last buildings are reserved for areas with very low susceptibility given their use as shelters in case of emergency. 
Acknowledgements. This study was supported by the Generalitat de Catalunya (RISKNAT research group SGR2001-00081) and by the Consolider Igenio 2010 programme, under CSD 2006 "Topo-Iberia". Aerial photographs and DEM were provided by the Instituto Nicaragüense de Estudios Territoriales, INETER. Field work would not have been possible without the logistical support provided by the Centro de Investigaciones Geocientíficas, CIGEO (Universidad Nacional Autónoma de Nicaragua, Managua). We are indebted to the local emergency committees and to the people from San Nicolas and Santa Rosa del Peñón communities for providing accommodation and support during the fieldwork.

Edited by: T. Glade

Reviewed by: C. van Westen and another anonymous referee

\section{References}

Ayalew, L., Yamagishi, H., and Ugawa, N.: Landslide susceptibility mapping using GIS-based weighted linear combination, the case in Tsugawa area of Agano River, Niigata Prefecture, Japa. Landslides, 1, 73-81, 2004.

Ayalew, L., Yamagishi, H., Marui, H., and Kanno, T.: Landslides in Sado Island of Japan: Part II. GIS-based susceptibility mapping with comparison of results from two methods and verifications, Eng. Geol., 81, 432-445, 2005.

Baeza, C. and Corominas, J.: Assessment of shallow landslide susceptibility by means of multivariate statistical techniques, Earth Surf. Proc. Land., 26, 1251-1263, 2001.

Bathurst, J. C., Burton, A., and Ward, T. J.: Debris flow run-out and landslide sediment delivery model tests, J. Hydraul. Eng., 123, 410-419, 1997.

Begueria, S.: Validation and evaluation of predictive models in hazard assessment and risk management, Nat. Hazards, 37, 315329, 2006

Carrara, A., Cardinali, M., Guzzetti, F., and Reichenbach, P.: GIS Technology in Mapping Landslide Hazard, in: Geographical Information Systems in Assessing Natural Hazards, edited by: Carrara, A. and Guzzetti, F., Academic Pub., Dordrecht, the Netherlands, 360 pp., 1995.

Chung, C. F. and Fabbri, A. G.: Validation of spatial prediction Models for Landslide Hazard Mapping, Nat. Hazards, 30, 451472, 2003.

Chung, C. F. and Fabbri, A. G.: Systematic procedures of landslide hazard mapping for risk assessment using spatial prediction models, in: Landslide Risk Assessment, edited by: Glade, T., Anderson, M. G., and Crozier, M. J., John Wiley, 139-174, 2005.

Coe, J. A., Godt, J. W., Baum, R. L., Bucknam, R. C., and Michael, J. A.: Landslide susceptibility from topography in Guatemala, in: Landslides: Evaluation and stabilization, edited by: Lacerda, W. A., Ehrlich, M., Fontura, S. A. B., Sayao, A. S. F., Taylor \& Francis Group, London, 1, 69-78, 2004.

Corominas, J.: The angle of reach as a mobility index for small and large landslides, Can. Geotech. J., 33, 260-271, 1996.

Corominas, J., Copons, R., Vilaplana, J. M., Altimir, J., and Amigó, J.: Integrated landslide susceptibility analysis and hazard assessment in the Principality of Andorra, Nat. Hazards, 30, 421-435, 2003.

Dai, F. C. and Lee, C. F.: Landslide characteristics and slope instability modelling using GIS, Lantau Island, Hong Kong, Geomor- phology, 42, 213-228, 2002.

Dai, F. C., Lee, C. F., and Ngai, Y. Y.: Landslide risk assessment and management: an overview, Eng. Geol., 64, 65-87, 2002.

Darce, M., Levi, B., Nyström, J. O., and Troëng, B.: Alteration patterns in volcanic rocks within an east-west transverse through central Nicaragua, J. S. Am. Earth Sci., 2, 155-161, 1989.

Duque, A., Echevarría, G., Kerejeta, A., Cendrero, A., and Tamés, P.: Comprobación empírica de metodologías para la elaboración de mapas de amenaza de inestabilidad de laderas; aproximación a un modelo general de evaluación del riesgo, in: Environmental geology and natural hazards in the Andean region, edited by: Hermelin, M., AGID Report no. 13, Pereira, Colombia, 189-206, 1990.

Ehrenborg, J.: A new estratigraphy for the Tertiary volcanic rocks of the Nicaraguan Highland, GSA Bull., 108, 830-842, 1996.

Fabbri, A., Chung, C. F., Cendrero, A., and Remondo, J.: Is prediction of future landslides possible with a GIS?, Nat. Hazards, 30, 487-499, 2003.

Fenzl, N.: Nicaragua, Geografía, Clima, Geología y Hidrogeología. UFPA/INETER/INAN, Belem (Eds). 62 pp., 1988.

Fernández, T., Irigaray, C., El Hamdouni, R., and Chacón, J.: Methodology for landslide susceptibility mapping by means of a GIS. Application to the Contraviesa Area (Granada, Spain), Nat. Hazards, 30, 297-308, 2003.

Guinau, M., Pallàs, R., and Vilaplana, J. M.: A feasible methodology for landslide susceptibility assessment in developing countries: A case-study of NW Nicaragua after Hurricane Match, Eng. Geol., 80, 316-327, 2005.

Guzzetti, F., Reichenbach, P., Ardizone, F., Cardinali, M., and Galli, M.: Estimating the quality of landslide susceptibility models, Geomorphology, 81, 166-184, 2006.

Hürlimann, M., Copons, R., and Altimir, J.: Detailed debris flow hazard assessment in Andorra: A multidisciplinary approach, Geomorphology, 78, 359-372, 2006.

INETER: Las lluvias del siglo en Nicaragua, Instituto Nicaragüense de Estudios Territoriales, INETER, Managua, Nicaragua, 159 pp., 1998.

Montgomery, D. R. and Dietrich, W. E.: A physically based model for the topographic control on shallow landsliding, Water Resour. Res., 30, 1153-1171, 1994.

Moore, I. D., Grayson, R. B., and Ladson, A. R.: Digital terrain modelling: a review of hydrological, geomorphological and biological applications, Hydrol. Process., 5, 3-30, 1991.

Pallàs, R., Vilaplana, J. M., Guinau, M., Falgàs, E., Alemany, X., and Muñoz, A.: A pragmatic approach to debris flow hazard mapping in areas affected by Hurricane Match: example from NW Nicaragua, Eng. Geol., 72, 57-72, 2004.

Parise, M. and Jibson, R. W.: A seismic landslide susceptibility rating of geologic units based on analysis of characteristics of landslides triggered by the 17 January, 1994 Northridge, California earthquake, Eng. Geol., 58, 251-270, 2000.

Remondo, J., González-Díez, A., Díaz de Terán, J. R., and Cendrero, A.: Landslide susceptibility models using spatial data analysis techniques. A case study from the Lower Deba Valley, Guipúzcoa (Spain), Nat. Hazards, 30, 267-279, 2003 a.

Remondo, J., González-Díez, A., Díaz de Terán, J. R., Cendrero, A., Fabbri, A., and Chung, C. F.: Validation of landslide susceptibility maps; examples and applications from a case study in Northern Spain, Nat. Hazards, 30, 437-449, 2003 b. 
Rickenmann, D.: Empirical relationships for debris flows, Nat. Hazards, 19, 47-77, 1999.

Saha, A. K., Gupta, R. P., Sarkar, I., Arora, M. K., and Csaplovics, E.: An approach for GIS-based statistical landslide susceptibility zonation - with a case study in the Himalayas, Landslides, 2, 61-69, 2005.

Santacana, N., Baeza, C., Corominas, J., de Paz, A., and Marturià, J.: A GIS-based multivariate statistical analysis for shallow landslide mapping in La Pobla de Lillet Area (Eastern Pyrenees, Spain), Nat. Hazards, 30, 281-295, 2003.

Süzen, M. and Doyuran, V.: A comparison of the GIS based landslide susceptibility assessment methods: multivariate versus bivariate, Environ. Geol., 45, 665-679, 2004.

Tarboton, D. G.: A new method for the determination of flow directions and upslope areas in grid digital elevation models, Water Resour. Res., 33, 309-319, 1997.

Tarolli, P. and Tarboton, D. G.: A new method for determination of most likely landslide initiation points and the evaluation of digital terrain model scale in terrain stability mapping, Hydrol. Earth Syst. Sci., 10, 663-677, 2006,

http://www.hydrol-earth-syst-sci.net/10/663/2006/. van Westen, C. J.: Application of Geographical Information Systems to Landslide Hazard Zonation, ITC Publication Number 15, Enschede, The Netherlands, 1993.

van Westen, C. J., Rengers, N., Terlien, M. T. J., and Soeters, R.: Prediction of the occurrence of slope instability phenomena through GIS-based hazard zonation, Geol. Rundsh., 86, 404 414, 1997.

Varnes, D. J.: Landslide Hazard Zonation: a review of principles and practice. IAEG Commission on Landslides and Other MassMovements, UNESCO Press, Paris, 63 pp., 1984.

Yin, K. L. and Yan, T. Z.: Statistical prediction model for slope instability of metamorphosed rocks, in: Landslides-Glissements de Terrain, Proceedings V International Symposium on Landslides, vol. 2, Lausanne, Switzerland, 1269-1272, 1988. 